\title{
A Fuzzy logic distance relay
}

\section{Maamoon Fadhel Al-Kababjie, Muhamed Nashwan Al-Kaleajie}

Electrical Engineering Department, University of Mosul, Mosul, Iraq

\section{Email address:}

al_kababjie@yahoo.com (M. F. Al-Kababjie), Muhamednashwan87@gmail.com (M. N. Al-Kaleajie)

\section{To cite this article:}

Maamoon Fadhel Al-Kababjie, Muhamed Nashwan Al-Kaleajie. A Fuzzy Logic Distance Relay. American Journal of Electrical Power and Energy Systems. Vol. 3, No. 5, 2014, pp. 95-100. doi: 10.11648/j.epes.20140305.12

\begin{abstract}
This paper presents a new approach to protect the transmission line by a design and implementation of distance relay using Fuzzy logic module. The proposed module uses sample of voltage and current signals to calculate line impedance $(\mathrm{ZL})$. Simulation studies are performed and influence of changing system parameters such as type of faults like single line to ground fault, three phase to ground fault and double line to ground fault, also fault resistance and fault location; were taken the results show that the module respond in a very high speed relay, the performance of this distance relay is fast and accurate as compared with other relays the detection is with in less than $1 / 8$ of the period.
\end{abstract}

Keywords: Transmission Line, Distance Relay, Fuzzy Logic, Matlab-Simulink

\section{Introduction}

Power transmission lines are vital links that provide continuity of fundamental services, from power plants to customers. And the transmission lines spread over large areas and it were exposed to different types of defects. To protect transmission lines against faults exposed is one of the most challenging tasks in the protection of the power system .the distance relays respond to the impedance between the relay and Error and Been applied on a large scale protection systems distance transmission line to protect the power system. By measuring the voltage and current signals.

It is known that distance relays, and in particular ground distance function measurements are affected by fault resistance. Fault resistance is an operational problem and is not a constant parameter in nature. It depends on various factors such as voltage level, tower footing resistance, resistivity of soil and environmental conditions. Fault resistance produces an error in the impedance measurement and thus could affect the accuracy of the relay severely. The relay may over-reach/under-reach, which can result in false tripping and error operation. Moreover, the relay measurements are affected by source impedances and system configuration changes. Adaptive protection relaying approaches have been proposed to consider these system changing variables. [1]

The use of fuzzy logic in applications is very sparse due to its implicit knowledge representation. The key benefit of fuzzy logic is that its knowledge representation is explicit, using simple "IF-THEN" type of relations. [2]

In this paper, describes a technique that distinguishes faults in a transmission line and protected it by design distance relay using Fuzzy logic, the proposed technique has also been analyzed. Some test results are also presented.

\section{A Distance Relays}

Since the impedance of a transmission line is proportional to its length, for distance measurement it is appropriate to use a relay capable of measuring the impedance of a line up to a predetermined point (the reach point). Such a relay is described as a distance relay and is designed to operate only for faults occurring between the relay location and the selected reach point, thus giving discrimination for faults that may occur in different line sections.

The basic principle of distance protection involves the division of the voltage at the relaying point by the measured current. The apparent impedance so calculated is compared with the reach point impedance. If the measured impedance is less than the reach point impedance, it is assumed that a fault exists on the line between the relay and the reach point. [3]

B Transmission Line Impedance:

Fig.1 may represent one of many fault condition in a three-phase power system. Point $\mathrm{R}$ represents the relay location; $I_{R}$ and $V_{R}$ are the current and voltage measured by the relay, respectively.

For faults involving earth path it is dependent on the system earthing behind the relaying point. Line impedance $Z_{L}$ is a measure of the impedance of the protected section. 
The voltage $V_{R}$ applied to the relay is, therefore, $I_{R} Z_{L}$. For a fault at the reach point, [3]

C Fuzzy Systems in power system protection:

The fuzzy signal processing and fuzzy reasoning techniques (belonging to the family of Artificial Intelligence) have gained remarkable attention for at least 15 years and numerous studies have been performed in world-leading research centers with regard to their application also for power system protection and control tasks. Fuzzy Logic systems (FL) are well suited for solving various decisionmaking problems, especially when the precise analytical model of the process object to be tracked is not known or is very complicated (e.g. non-linear). [4] The operation principle of fuzzy logic controller is similar to a human operator. It performs the same actions as a human operator does by adjusting the input signal looking at only the system output. Fuzzy logic has three steps as shown in Fig.(2): [5]

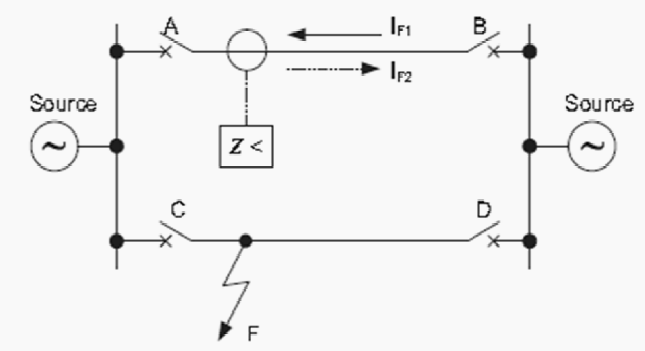

Fig (1). Double circuit transmission line.

1. Fuzzification (Converting crisp values into fuzzy values).

2. Inference mechanism (Rule base and If-Then rules).
3. Defuzzification (Converting fuzzy values into crisp values).

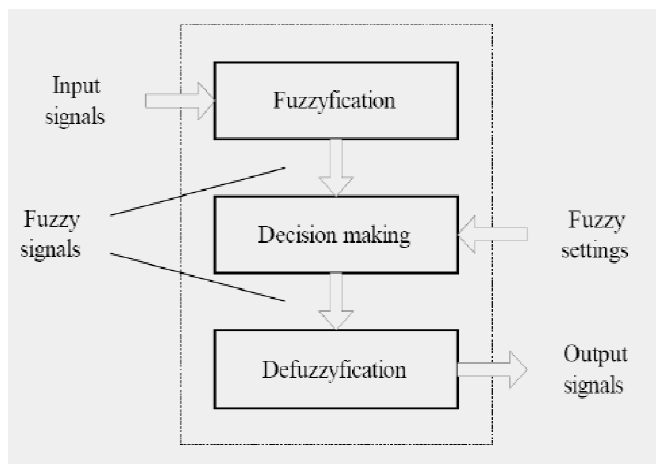

Fig (2). Basic structure of the Fuzzy logic.

\section{Fuzzy Logic Based Distance Protection Relay}

The Fuzzy logic that use in the distance relay that proposed shown in Fig. (3), the advantage of fuzzy logic to issue trip decision, depending on training input output data, shown in Fig. (4) and Fig. (5).

The inference method, which is used in design the proposed relay, was Takagi- Sugeno's. The proposed relay scheme has been tested on a variety of processes as designed depending on training input-output data. Fig.(6) shows the three dimensions input output characteristics of proposed distance intelligent relay,

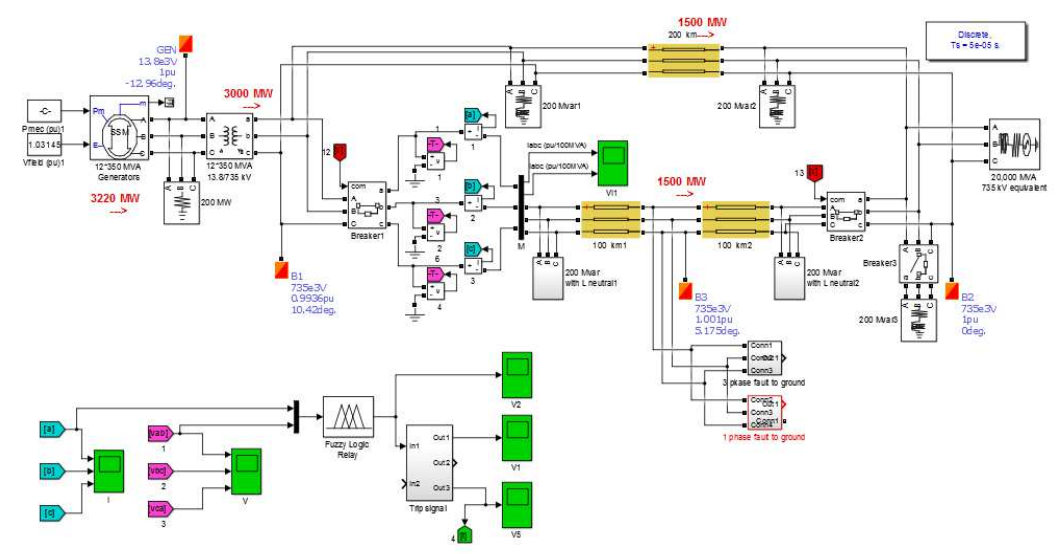

Fig (3). Distance relay based on Fuzzy logic

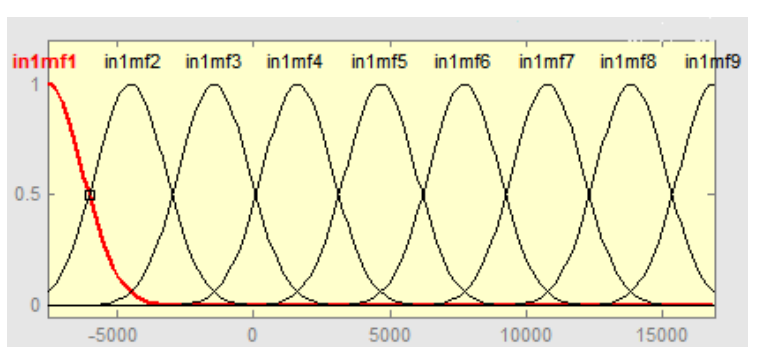

Fig (4). Fuzzy input membership function for voltage (V).

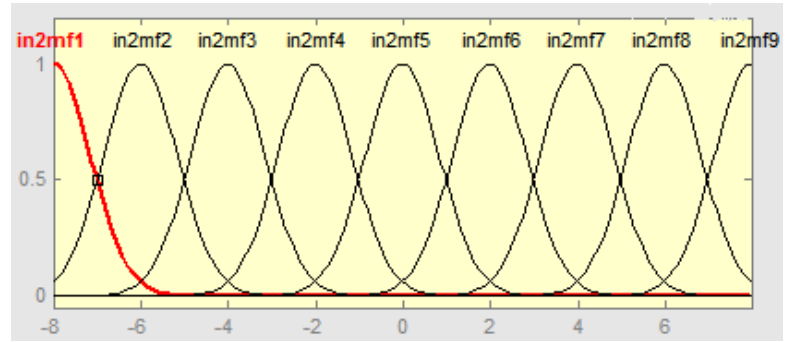

Fig (5). Fuzzy input membership function for current (I). 


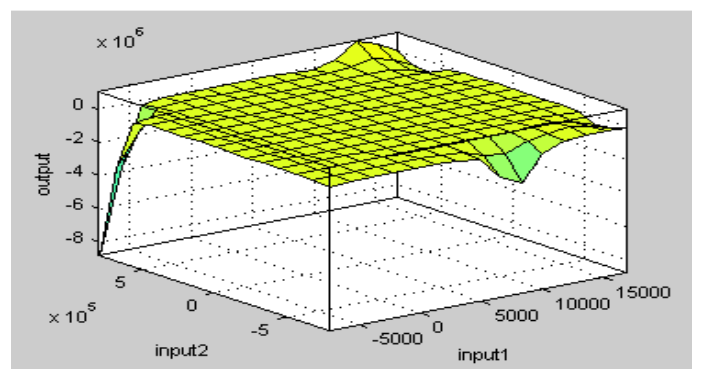

Fig (6). Three dimensions input output characteristics

The intelligent proposed relay as modeled in MatlabSimulink 2013b, which has two fuzzy variables voltage (V) and current (I) and nine linguistic variables for each, from very low to very high, as shown in Fig. (4) and (5). The fuzzy logic based distance protection proposed relay attributes and all details are given in following summary.

\section{The Characteristic of Distance Relay}

Some numerical relays measure the absolute fault impedance and then determine whether operation is required according to impedance boundaries defined on the $\mathrm{R} / \mathrm{X}$ diagram. Traditional distance relays and numerical relays that emulate the impedance elements of traditional relays do not measure absolute impedance. They compare the measured fault voltage with a replica voltage derived from the fault current and the zone impedance setting to determine whether the fault is within zone or out-of-zone. Distance relay impedance comparators or algorithms which emulate traditional comparators are classified according to their polar characteristics, the number of signal inputs they have, and the method by which signal comparisons are made. The common types compare either the relative amplitude or phase of two input quantities to obtain operating characteristics that are either straight lines or circles when plotted on an R/X diagram [3]. As shown in Fig. (7).

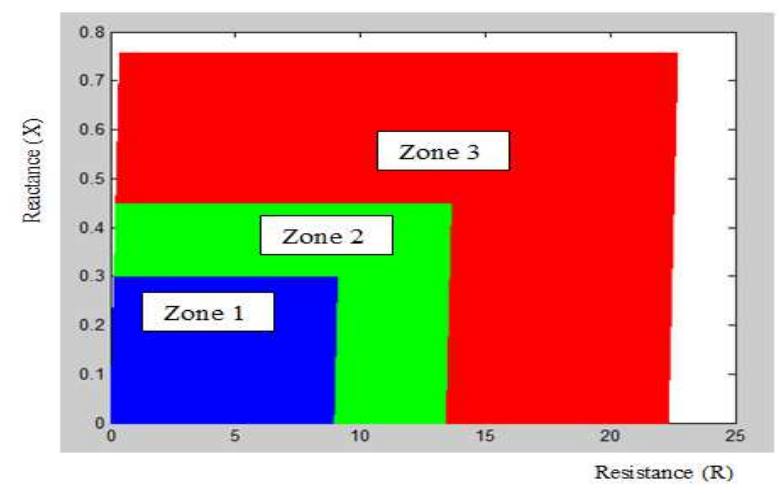

Fig (7). The characteristic of distance relay.

\section{The Simulink Results for Distance Relay that Proposed}

Fig. (3) Shows a typical $735 \mathrm{kV}$ transmission line double circuit and feed from tow end. This model is set up in
Simulink and simulated by generating several faults. The faults are generated at different locations with variable fault resistance and fault duration. Throughout the simulation, ground resistivity is taken to be $30 \Omega \mathrm{m}$ which is practically acceptable.

And also with the arc resistance by using arc model with it.

\subsection{Single Line to Ground Fault at $70 \%$ of the Line with Resistance Fault $20 \mathrm{ohm}$, the Result Shown in the} Fig. $(8,9,10$, and 11)

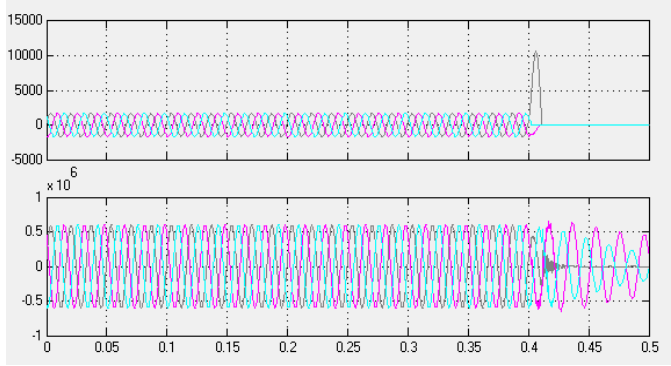

Fig (8). Voltage and current signals for phase a to ground fault at $70 \mathrm{Km}$

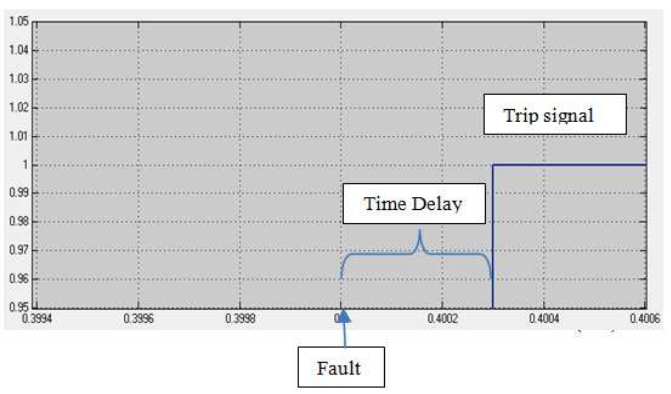

Fig (9). Trip signal with time delay

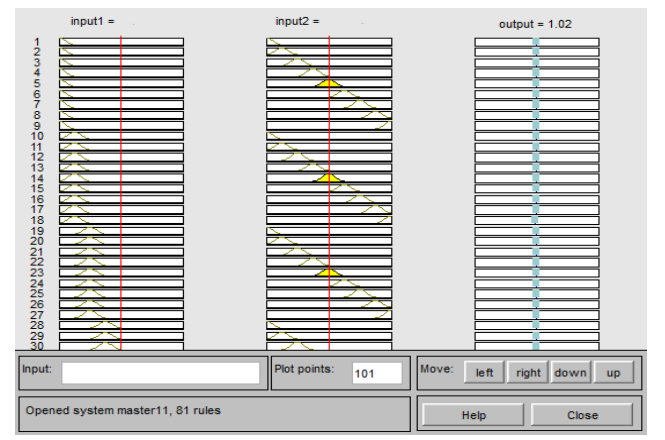

Fig (10). The results of membership function and Sugeno corresponding response

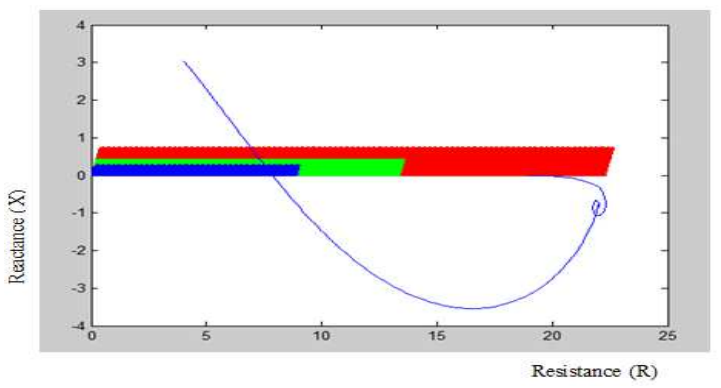

Fig (11). Fault impedance locus for fault at $70 \mathrm{~km}$ from substation terminal with fault resistance $20 \mathrm{ohm}$. 


\subsection{Single Line to Ground Fault at 125\% of the Line with} Fault Resistance $30 \mathrm{ohm}$, the Result Shown in Fig (12, 13, and 14).

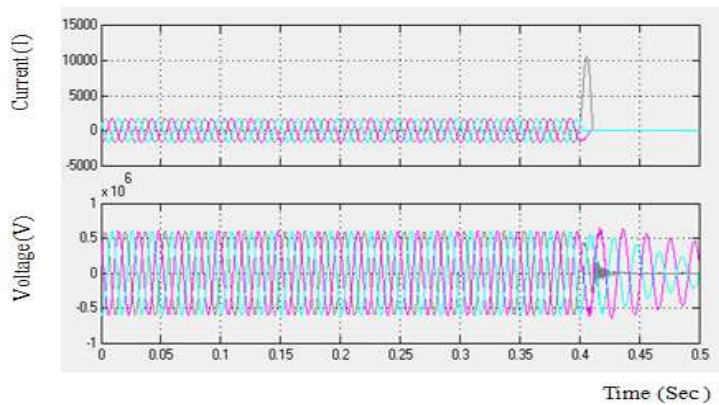

Fig (12). Voltage and current signals for phase a to ground fault at $125 \mathrm{Km}$

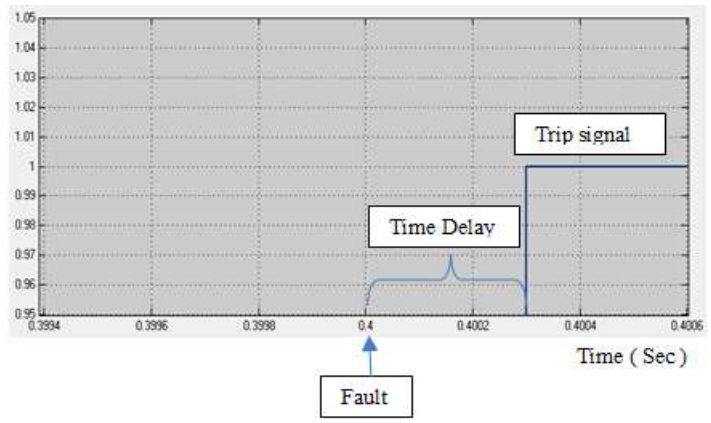

Fig (13). Trip signal with time delay

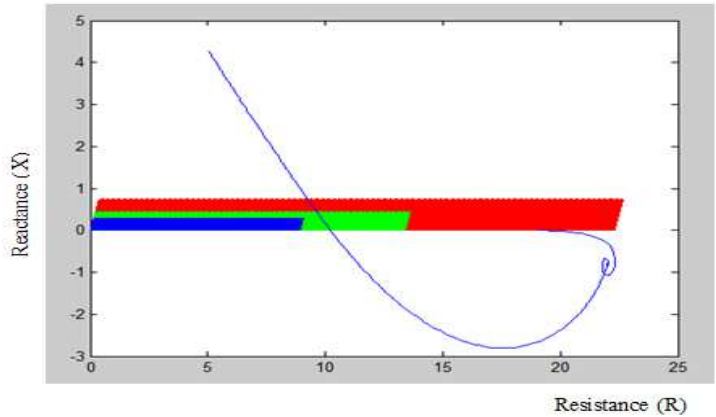

Fig (14). Fault impedance locus for fault at $125 \mathrm{~km}$ from substation terminal with fault resistance $30 \mathrm{ohm}$.

\subsection{Single line to Ground Fault at $170 \%$ of the Line with} Fault Resistance $25 \mathrm{ohm}$, the Result Shown in

Fig $(15,16$, and 17)

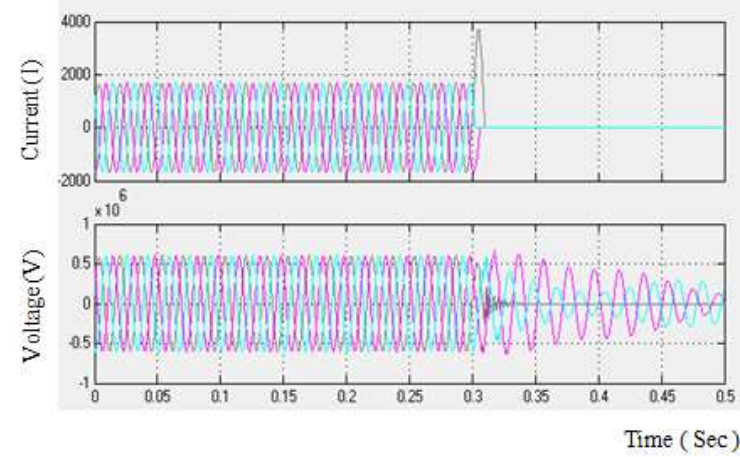

Fig (15). Voltage and current signals for phase a to ground fault at $170 \mathrm{Km}$

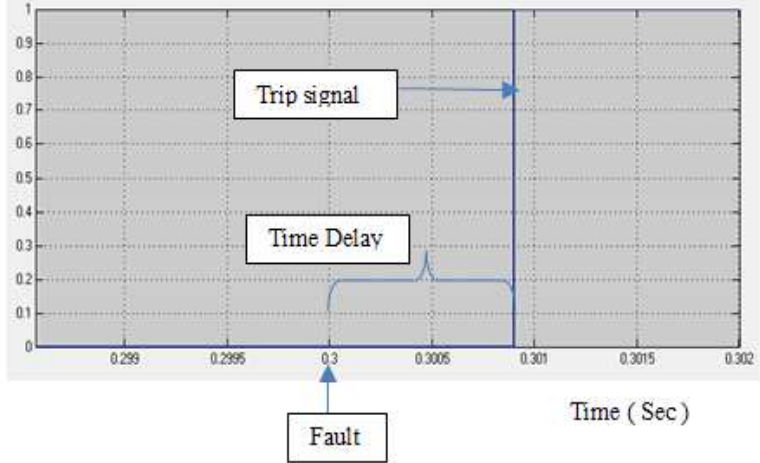

Fig (16). Trip signal with time delay

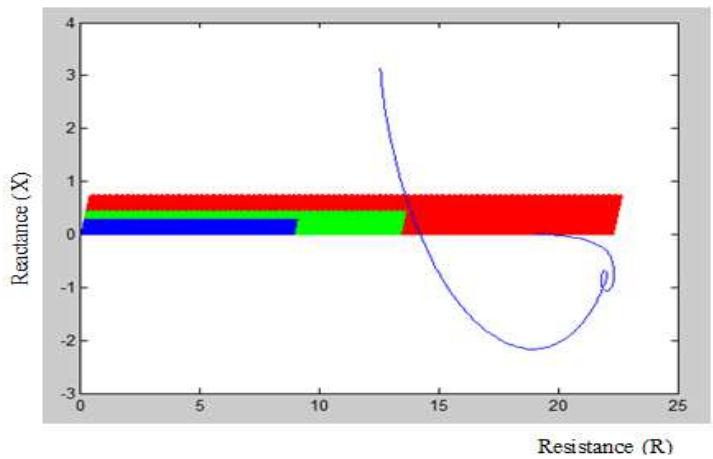

Fig (17). Fault impedance locus for fault at $170 \mathrm{~km}$ from substation terminal with fault resistance $25 \mathrm{ohm}$.

\subsection{Three Phase to Ground Fault at $60 \%$ of Line with Fault Resistance 10 ohm, the Result Shown in Fig.} $(18,19$, and 20)

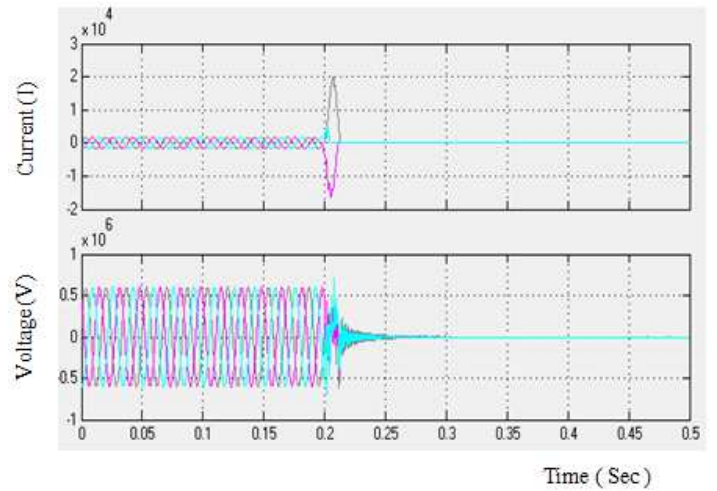

Fig (18). Voltage and current signals for three phase to ground fault at 60 Km

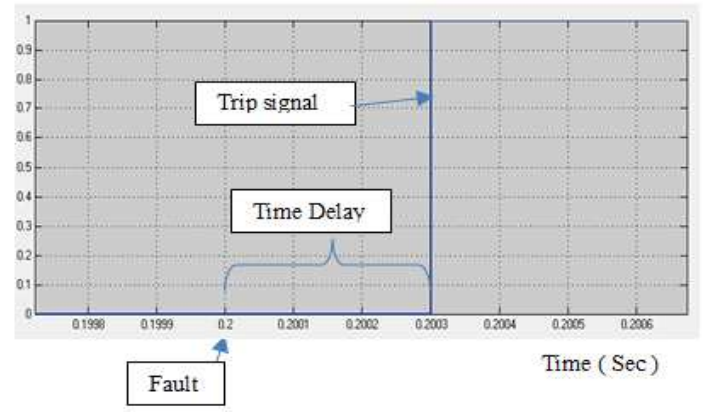

Fig (19). Trip signal with time delay 


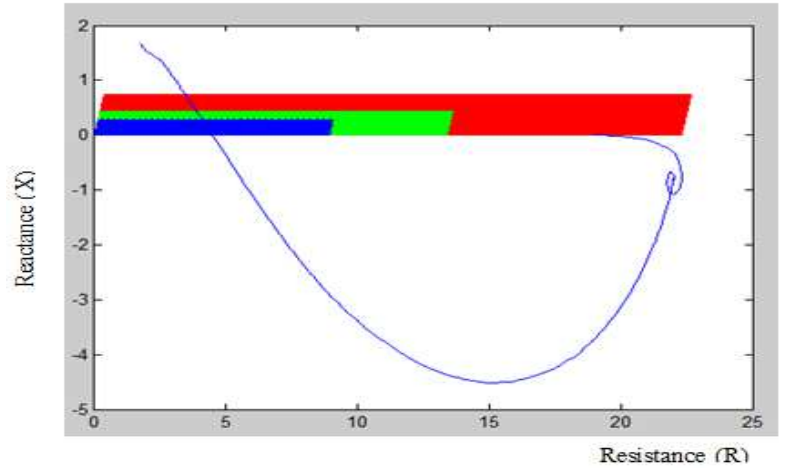

Fig (20). Fault impedance locus for fault at $60 \mathrm{~km}$ from substation terminal with three phase fault resistance $10 \mathrm{ohm}$.

4.5. Single Phase to Ground Fault at $135 \%$ of Line with the Arc Model, the Result Shown in Fig (21, 22, and 23)

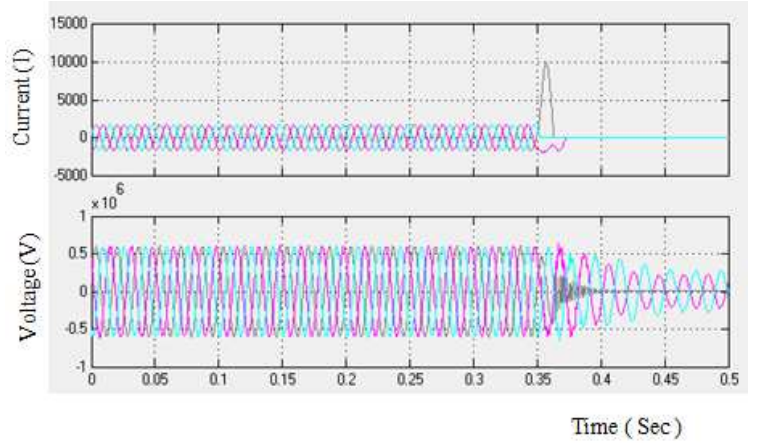

Fig (21). Voltage and current signals for three phase to ground fault at 135 $\mathrm{Km}$

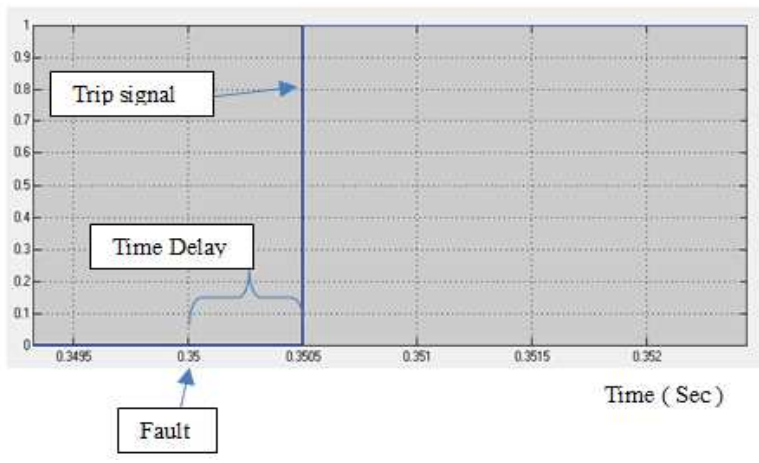

Fig (22). Trip signal with time delay

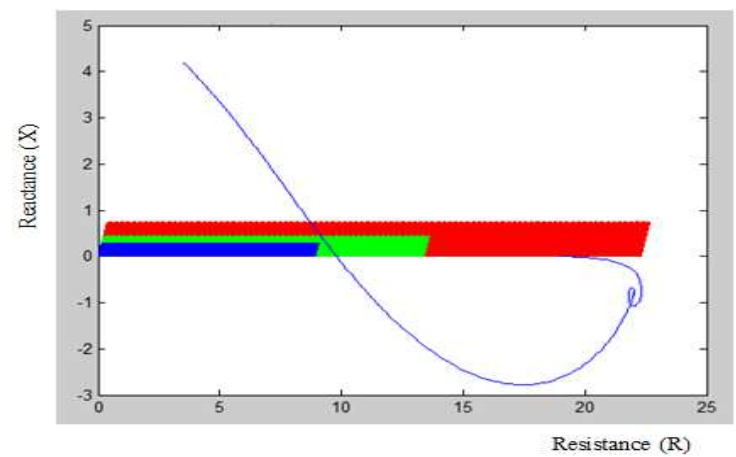

Fig (23). Fault impedance locus for fault at $135 \mathrm{~km}$ from substation terminal with arc model.

\subsection{Three Phase to Ground Fault at $80 \%$ of Line with Arc} Model, the Result Shown in Fig. (24, 25, and 26)

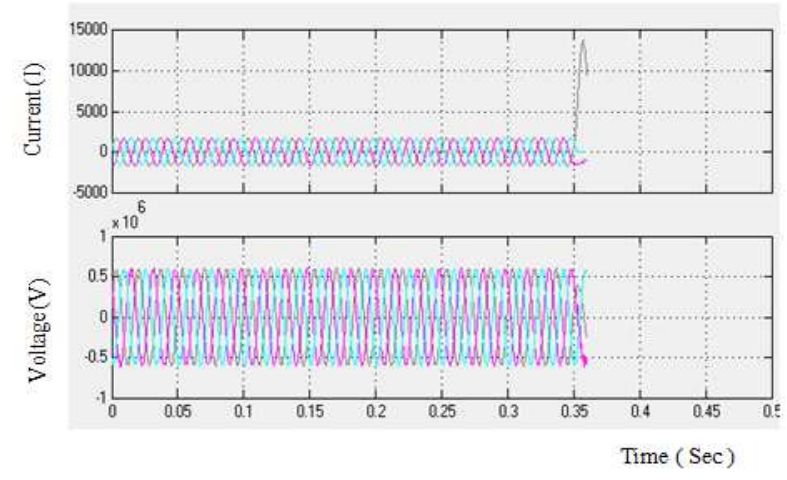

Fig (24). Voltage and current signals for three phase to ground fault at 80 $\mathrm{Km}$

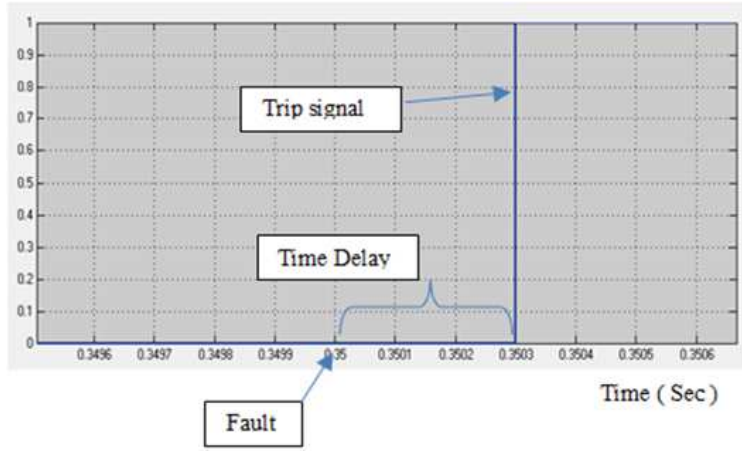

Fig (25). Trip signal with time delay

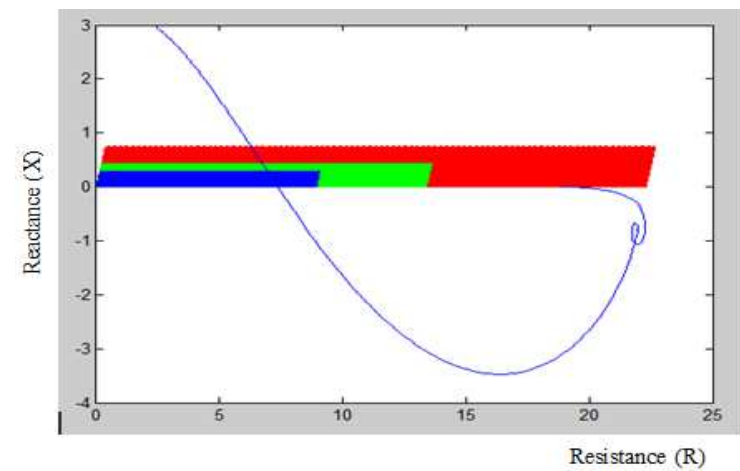

Fig (26). Fault impedance locus for three phase fault at $80 \mathrm{~km}$ from substation terminal with arc model.

\section{Conclusions}

The use of Fuzzy logic to improve the performance of distance relay is discussed in this paper. The developed Fuzzy logic is able to detect the fault in the different system condition. The results shows a very good performance in the different fault condition, the distance relay prove to be fast and accurate for various system conditions. We can say that the distance relay designed can be implemented in an actual power system, and I am trying to make this relay works as a universal relay, that's mean it can work with different levels of voltage system like ( $750 \mathrm{kv}, 400 \mathrm{kv}, 132 \mathrm{kv}, 66 \mathrm{kv}$ and $33 \mathrm{kv}$ ) without make any change in the setting of the relay 


\section{References}

[1] M. Sanaye-Pasand, and H . Khorashadi-Zadeh, An Extended ANN-Based High Speed Accurate Distance Protection Algorithm, Electrical Power and Energy Systems 25, January, 2006.

[2] M. F. Al-Kababji, Real Time Based Fuzzy Logic Distance Protection, Al-Rafidain engineering, Vol.20, No. 3, June, 2012.

[3] Network Protection and Automation Guide, Alstom grid, May, 2011.

[4] W. W. L. Keerthipala , Huisheng Wang, Chan Tat Wai, OnLine Testing of a Fuzzy-Nleuro based Protective Relay using a Real-Time Digital Simulator, IEEE, Journal: Power Engineering Society Winter Meeting, vol .3,2000.

[5] K. Erenturk, A New Digital Protective Relay Based on Fuzzy Logic and Value Estimation, Iranian Journal of Science and Technology, transaction A, Vol.29, No.A2, 2005. 